\title{
Bir Üretim İşletmesinde Simülasyon Yöntemi ile Darboğaz Analizi ve Sistem İyileştirmesi
}

\author{
Ege Cihangir ${ }^{1}$, Fatma Demircan Keskin ${ }^{2 *}$, Ural Gökay Çiçekli ${ }^{3}$, Gökhan Yakan ${ }^{4}$ \\ ${ }^{1}$ Ege Üniversitesi, Sosyal Bilimler Enstitüsü, İzmir, Türkiye, (ORCID: 0000-0002-2294-1122), egecihangirr@gmail.com \\ ${ }^{2 *}$ Ege Üniversitesi, İktisadi ve İdari Bilimler Fakültesi, İşletme Bölümü, İzmir, Türkiye (ORCID: 0000-0002-7000-4731), fatma.demircan.keskin@ege.edu.tr \\ ${ }^{3}$ Ege Üniversitesi, İktisadi ve İdari Bilimler Fakültesi, İşletme Bölümü, İzmir, Türkiye (ORCID: 0000-0002-6032-9540), gokay.cicekli@ege.edu.tr \\ ${ }^{4}$ Volt Elektrik Motorları, İzmir,Türkiye, Türkiye (ORCID: 0000-0002-6619-3138), gokhan.yakan@voltmotor.com.tr
}

(1st International Conference on Applied Engineering and Natural Sciences ICAENS 2021, November 1-3, 2021)

(DOI: 10.31590/ejosat.1012214)

ATIF/REFERENCE: Cihangir, E., Demircan Keskin, F., Çiçekli, U.G. \& Yakan, G. (2021). Bir Üretim İşletmesinde Simülasyon Yöntemi ile Darboğaz Analizi ve Sistem İyileştirmesi. Avrupa Bilim ve Teknoloji Dergisi, (28), 917-923.

$\ddot{\mathrm{O} z}$

Üretim süreçlerinde iyileştirmelerin yapılabilmesi ve performans artışının sağlanabilmesi için sistemin mevcut durumunun gerçek süreç verileriyle ortaya konması ve süreçte aksaklık yaratan noktaların tespit edilebilmesi gerekmektedir. Üretim sistemlerinde mevcut durumun analiz edilmesi, darboğazların belirlenmesi, çıktı miktarı ve kaynak kullanımını iyileştirecek önerilerin ortaya konması ve değerlendirilebilmesinde simülasyon sıklıkla başvurulan bir yöntemdir. Bu çalı̧̧mada elektrik motoru üreten bir firmanın bir stator yarı mamul üretim hattının, AnyLogic yazılımı kullanılarak kesikli olay simülasyon modeli geliştirilmiştir. Ele alınan hatta 8 makine ve 11 operatör kaynağ kullanılarak akış tipi üretim gerçekleştirilmektedir. Model ile darboğaz belirleme ve hatta kaynak kullanım oranlarını maksimize eden ve stok maliyetlerini minimize eden akışın oluşturulması amaçlanmaktadır. Model parametreleri, hatta iliş̧kin geçmiş bir yıllık veriler kullanılarak yapılan girdi analizi ile hazırlanmıştır. Simülasyon modelinin çalıştırılması ile mevcut durum analiz edilmiştir. Bulgular, hatta yer alan sarım makinesinin darboğaz olduğuna işaret etmektedir. Sistem performansını iyileştirmek için, hattın verimliliği ve kaynakların kullanım oranlarına odaklanılarak, sarım makinesinin ideal üretim miktarı belirlenmiştir. Ayrıca, hat için yeni bir yerleşim önerisinde bulunularak bu önerinin operatör kullanım oranına katkısı değerlendirilmiş̧ir.

Anahtar Kelimeler: Kesikli olay simülasyonu, AnyLogic, Darboğaz analizi, Kaynak kullanımı, Çıktı miktarı, Sistem iyileştirme.

\section{Bottleneck Analysis and System Improvement with Simulation Method in a Manufacturing Facility}

\begin{abstract}
Achieving improvements in production processes requires analyzing the processes and identifying bottlenecks based on actual process data. Simulation is a widely applied method in analyzing the current state of production systems, identifying bottlenecks, developing alternative scenarios to improve throughput and resource utilization, and evaluating these scenarios' performances. In this study, a discrete event simulation model of a stator production line of a company that produces electrical motors has been developed using AnyLogic software. The analyzed production line is a flow-type production line that consists of 8 machines and 11 operators. This study aims to detect the bottlenecks and determine a flow that maximizes resource utilization rates and minimizes inventory holding costs. The model parameters have been prepared with input analysis using the actual data from the past year of the line. The current state of the line revealed by running the simulation model has been analyzed. The findings have indicated that the winding machine is the bottleneck of the production line. The ideal production quantity of the winding machine has been determined by focusing on the productivity of the line and the utilization rates of resources to improve the system performance. Moreover, an alternative layout for the line has been suggested. Finally, the projected gains with this layout have been evaluated in terms of operator utilization rate.
\end{abstract}

Keywords: Discrete event simulation, AnyLogic, Bottleneck analysis, Resource utilization, Throughput, Process improvement.

* Sorumlu Yazar: fatma.demircan.keskin@ege.edu.tr 


\section{Giriş}

Üretim sistemleri, mekanik üretim sistemlerinin ortaya çıktığı birinci sanayi devriminden günümüze gelinceye kadar evrimsel değişimlere uğramıștır. Günümüzde, özellikle siber fiziksel sistemler ve nesnelerin interneti gibi teknolojilerin gelişmesi ve imalat sistemlerine entegre olması ile Endüstri 4.0 olarak adlandırılan üretim anlayışın temeli atılmıştır [1]. $\mathrm{Bu}$ anlayış üretim sistemlerinin, atölye düzeyinden çekilen verilere dayalı olarak kararlar almasını, değişen koşullara hızlı adapte olunmasını ve yüksek düzey esnekliği gerektirmektedir [2]. Bunun için üretim sistemlerinden elde edilen çıktı miktarını, maliyeti minimum düzeyde tutarak geliştirebilmek büyük önem taşımaktadır [3].

Üretim yönetiminde en kritik noktalardan biri, bir üretim sistemi içinde aksaklık yaratan faktörleri belirleyip onları ortadan kaldırmak için doğru kararları alarak sistem performansını artırabilmektir [4]. Bir sistemin kısitlarını belirlemeyi ve amaca olan etkilerine göre en önemli kısıtlardan başlanarak yapılacak iyileştirmelerin sistemin performansını önemli düzeyde artırılabileceğini ifade eden Kısıtlar Teorisi [5], bu noktada önemli bir yol göstericidir.

Bir sistemdeki tıkanıklık noktasını ifade eden darboğaz, içinde bulunduğu sistemin daha fazla çıktı elde etmesini engellemekte ve sistemin kapasitesini kisitlamaktadır [6]. Literatürde çok sayıda farklı tanımı bulunan darboğaz, genel sistem performansı üzerinde, azaltıcı etkisi en yüksek olan makine ya da kaynak olarak tanımlanabilmektedir [7].

Bir üretim hattında darboğazları belirleyip, bu nokta ya da noktalarda iyileştirmeler yapmak tüm sistemin performansını önemli bir düzeyde iyileştirebileceği için oldukça büyük önem taşımaktadır. Literatürde darboğaz belirleme, çıktı miktarını ve kaynakların kullanım oranlarını artırma gibi amaçlara yönelik gerçekleştirilen çalışmalarda simülasyon tabanlı yöntemler ön plana çıkmaktadır ([8][10]).

$\mathrm{Bu}$ çalışmada, elektrik motoru üreten bir firmanın stator yarı mamul üretim hatlarından birinin kesikli olay simülasyonu gerçekleştirilmiştir. Geliştirilen simülasyon modeli ile hattın darboğazının belirlenmesi ve hatta kaynak kullanım oranlarını maksimize eden ve stok maliyetlerini minimize eden akışın oluşturulması amaçlanmaktadır. $\mathrm{Bu}$ doğrultuda, ele alınan hatta ilişkin geçmiş bir yıllık veri kullanılarak yapılan girdi analizi ile model parametreleri hazırlanmış ve simülasyon modeli oluşturularak mevcut durum ortaya konmuştur. Mevcut durum analizi sonrası ele alınan hat için bir yerleşim önerisinde bulunulmuş ve bu önerinin operatör kullanım oranına katkısı değerlendirilmiştir. Çalışmanın bir sonraki bölümünde, bu çalışmanın amacıyla örtüşen ve simülasyon uygulaması yapan geçmiş çalışmalar sunulmaktadır. Üçüncü bölümde, ele alınan probleme ve geliştirilen simülasyon modeline ilişkin tüm detaylara yer verilmektedir. Modelin çalıştııılması ile elde edilen bulgular ve sürece ilişkin iyileştirme önerisi dördüncü bölümde sunulmaktadır. Çalışma, elde edilen sonuçlara ilişkin değerlendirmeler ile sonlandırılmaktadır.

\section{2. Önceki Çalışmalar}

Literatürde, üretim sistemlerinde çeşitli performans ölçütlerine odaklanarak süreç iyileştirmeyi amaçlayan birçok çalışmada simülasyon tabanlı yaklaşımlar uygulanmıştır. [11] geleneksel üretim anlayışını uygulayan bir imalat işletmesinde, yalın üretim uygulamalarının üretimin akışına ve yarı mamul stok miktarına etkilerinin ne olacağını değerlendirebilmek için simülasyondan yararlanmışlardır. [12] bir firmanın bobinaj üretim sürecinde verimliliği artırmak amacıyla iş etüdü ve zaman etüdü çalışmaları gerçekleştirmiştir. Çalışmalarında bobinaj üretim sürecinin çevrim süresini belirleyip, bu süreyi düşürmek için hattın yerleşiminde ve süreçte çeşitli iyileştirme önerilerinde bulunmuşlardır. Mevcut durum ve önerilen durumun performansını analiz etmişlerdir.

$\mathrm{Bu}$ çalışmada da kullanılan AnyLogic yazılımını, imalat süreçlerinin simüle edilmesinde uygulayan çok sayıda çalışma bulunmaktadır. [13] bir üretim hattını, hatta ilişkin bir y1llık geçmiş veriyi kullanarak kesikli olay simülasyonu ile modellemişlerdir. Mevcut durum analizini takiben, tespit edilen darboğazları ortadan kaldırmaya ve elde edilen çıktı miktarını artırmaya yönelik çeşitli iyileştirme senaryoları önermişlerdir. [14] elektrik motoru fren diskleri için plaka üreten bir firmanın bir üretim çevrimini simüle etmişlerdir. Mevcut durum ile hatta eklenmesini önerdikleri konveyörün yerleştirilmesi durumunda üretim miktarı ve yarı mamul stok miktarının nasıl değişeceğini geliștirdikleri simülasyon modelini çalıştırarak karşılaştırmışlardır. [15] çeşitli montaj hattı konfigürasyonlarının denge durumundaki etkinlik seviyelerini, davranışsal ve yorgunluk ile ilgili birtakım faktörlerin etkisini de göz önünde bulundurarak simülasyon uygulaması ile karşılaştırmışlardır. [16] işlenmiş ahşap ürünler üreten bir işletmede, üretim sürecinin mevcut durumunu analiz etmek ve yerleşimde ve operatör atamalarında yapılabilecek değişikliklerin çıktı miktarı üzerindeki etkilerini değerlendirmek için AnyLogic yazılımını kullanarak bir kesikli olay simülasyon modeli geliştirmişlerdir. AnyLogic yazılımını kullanan bir diğer çalışmada [17] bir hassas imalat firmasının otomatik depolama ve boşaltma sistemlerine yatırım yapması durumunda çıktı performansının ne düzeyde olacağını, etmen tabanlı modelleme ve kesikli olay simülasyonunun birlikte kullanarak modellemişlerdir. Başka bir çalışmada ise, [18] bir yariletken plaka üretim fabrikasının ön montaj sürecini, mevcut durumda uygulanan üretim partilerini serbest birakma politikalarını analiz etmek ve süreci iyileştirmek amacıyla ele almışlardır. Çalışmalarında gerçek süreç verilerine dayalı olarak geliştirdikleri simülasyon modeli ile mevcut durumu analiz etmişler, kaynak kullanım oranı, çıktı miktarı ve zamanında teslimat oranında önemli iyileştirmeler sağlayan öneriler ortaya koymuşlardır.

\section{Simülasyon Modeli}

Simülasyon mevcut ya da planlanan bir sistemin performansını tahmin etmek ve belirli bir problemin alternatif çözümlerini karşılaştırmak için kullanılabilmektedir. Bu çalışmada, AnyLogic yazılımı kullanarak bir üretim hattının kesikli olay simülasyonu gerçekleştirilmiştir. AnyLogic, kesikli olay simülasyonu, etmen tabanlı simülasyon ve sistem dinamiği gibi çeşitli simülasyon yöntemlerini barındıran, çok yöntemli bir simülasyon yazılımıdır [19]. AnyLogic çeşitli uygulamalar için oldukça esnek bir modelleme ortamı 
sunmaktadır. Kesikli olay simülasyon tekniği, karmaşık üretim sistemlerinin modellenmesi için çok uygundur [20]. Bu sebeple, bu çalışmada kesikli olay simülasyon aracı olarak AnyLogic kullanılmıştır.

\subsection{Model Açıklaması}

Elektrik moturu üreten bir fabrikada gerçekleştirilen uygulama, stator yarı mamulünün üretildiği bir üretim hattının simülasyonunu kapsamaktadır. Oluşturulan simülasyon modeli, gerçek dünyanın stokastik yapısını gösteren verilere dayanmaktadır. Üretim sisteminin sınırlarını, neden-sonuç ilişkilerini ve kısıtlarını içermektedir.

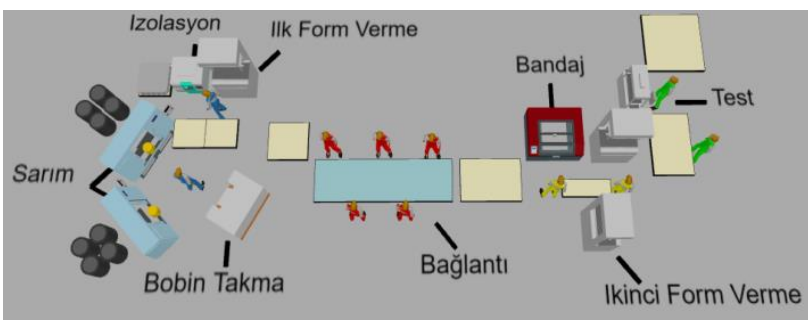

Şekil 1. Modelin üç boyutlu gösterimi

Ürünün iş istasyonlarında takip ettiği sıra da Şekil 2'de paylaşılmıştır:

Akış tipi üretimin gerçekleştiği hatta, 8 adet makine, 11 adet operatör kaynağı bulunmaktadır. Simülasyon modelinin üç boyutlu görseli Şekil 1'de gösterilmiştir:

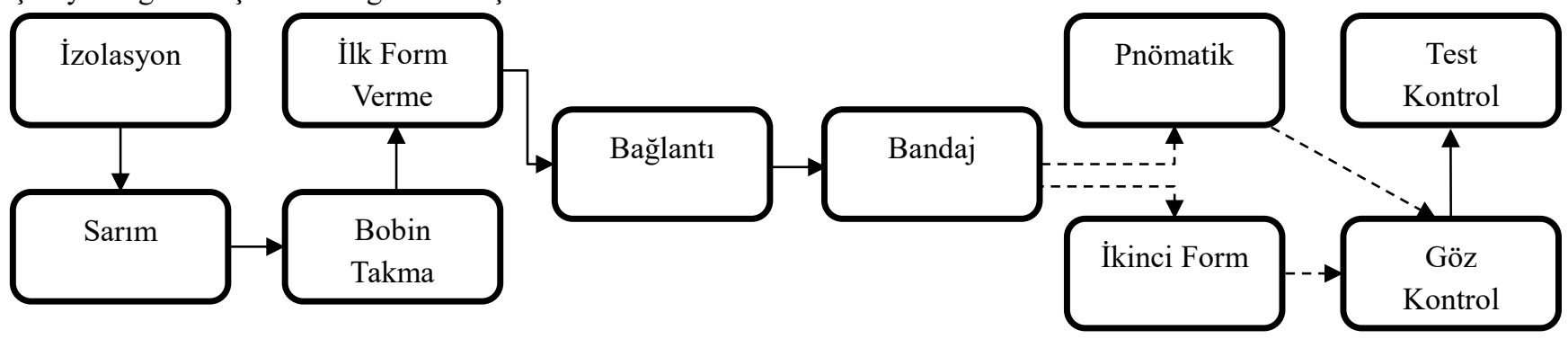

Şekil 2. Ürünün iş istasyonları arası akışı

Bir önceki süreçten gelen statorlar, izolasyonun önüne getirilir. İzolasyon operasyonu gerçekleştirilen stator ile, sarım istasyonunda transfer şişlerine sarılan bobin telleri, bobin takma operasyonunda birleştirilmektedir. İlk form verme sonrası bağlantı operasyonu yapılmaktadır (sırasıyla bağlantı $1,2,3,4$ ve 5). Daha sonra bandajlama yapılır ve ürünün türüne göre pnömatik form verme ya da ikinci form vermeye yönlendirilir. Ardından göz kontrol ve test kontrol yapılır ve hattın üretimi tamamlanır.

\subsection{Model Parametreleri}

Kurgusu tamamlanan modele ait parametreler bu bölümde anlatılmıştır.

Amaç: Üretim hattında yer alan kaynakların üretim hızları değişkenlik göstermektedir. $\mathrm{Bu}$ durum, bazı kaynakların kullanım oranlarının düşük olmasına, bazı kaynakların da önünde stok birikmesine sebebiyet vermektedir. Simülasyonla, üretim hattında darboğaz analizi gerçekleştirilerek, kaynak kullanım oranlarını maksimize eden ve stok maliyetini minimize eden akışın oluşturulması hedeflenmiştir.

Üretim yöneticileri sarım makinesini hat darboğazı olarak gözlemlemiş, hattaki diğer kaynakları günde 2 vardiya çalıştırırken, sarım makinesini 3 vardiya çalıştırma kararı almışlardır. Ancak bu karar, 3. vardiya çalışan sarım makinesinin ne kadar üretim yapması gerektiği ile ilgili net değildir. Belli bir miktarın üzerinde üretim yapması stok maliyetine yol açacak, belli bir miktarın altında gerçekleştirilen üretim de sonraki makine ve insan kaynağının kullanım oranlarının düşmesine sebep olacaktır.

Veriler: 1 aylık üretim planının, stok kodu bazında talep miktarları modele eklenmiştir.

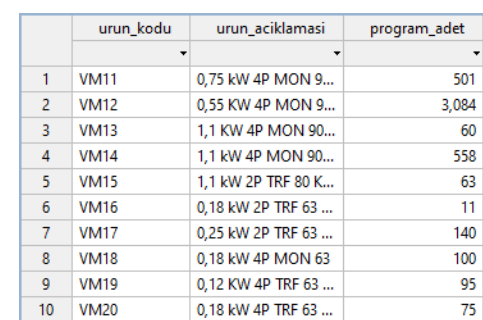

Şekil 3. Modele eklenen üretim planından bir kesit

Gerçek hayatın stokastik doğasını modele yansıtabilmek adına geçmiş bir yılın verileri kullanılmıştır. İş merkezlerine ait operasyon süreleri, makinelerin arıza olasılıkları ve tamir süreleri, ürünler arası geçişlerdeki makine hazırlık süreleri gibi parametreler olasılık dağılımları ile modele entegre edilmiştir. Bunun için Arena yazılımının Input Analyzer aracı kullanılmıştır. Örnek olması adına, aşağıdaki tablolarda bazı süreler, arıza zamanları ve tekrarları ile tezgah hazırlık zamanları olasılık dağılımlarıyla paylaşılmıştır.

Tablo 1. Sarım operasyonu süre dă̆llımı

\begin{tabular}{|c|c|}
\hline & Bobin Sarım \\
\hline $\mathbf{6 3}$ & $53+\operatorname{WEIB}(32.8,2.4)$ \\
\hline $\mathbf{7 1}$ & $40+\operatorname{LOGN}(34.2,24.6)$ \\
\hline $\mathbf{8 0}$ & $32+\operatorname{ERLA}(6.87,6)$ \\
\hline $\mathbf{9 0}$ & $42+\operatorname{GAMM}(16.5,2.06)$ \\
\hline $\mathbf{1 0 0}$ & $48+\operatorname{GAMM}(15.5,2.31)$ \\
\hline $\mathbf{1 1 2}$ & $58+\operatorname{LOGN}(44.6,37.6)$ \\
\hline $\mathbf{1 3 2}$ & $65+\operatorname{WEIB}(47.9,1.58)$ \\
\hline
\end{tabular}


Tablo 2. Bazı tezgahlardaki arıza süreleri ve tekrar sıklıkları

\begin{tabular}{|c|c|c|}
\hline & Arıza süresi & Tekrar Sayısı (gün) \\
\hline Sarım & $17+\operatorname{WEIB}(140,1.87)$ & uniform_discr(1, 12) \\
\hline $\begin{array}{c}\text { İlk Form } \\
\text { Verme }\end{array}$ & $\operatorname{LOGN}(36.5,47.9)$ & uniform_discr(1, 5) \\
\hline Bandaj & $\operatorname{WEIB}(47.7,1.35)$ & uniform_discr(1, 10) \\
\hline $\begin{array}{c}\text { İkinci } \\
\text { Form } \\
\text { Verme }\end{array}$ & $396 * \operatorname{BETA}(0.778$, & uniform_discr(1, 5) \\
\hline Test & GAMM $(10.1,2.69)$ & uniform_discr(1, 5) \\
\hline
\end{tabular}

\subsection{Modelin Doğrulanması ve Geçerliliğinin Test Edilmesi}

Oluşturulan kesikli olay simülasyonunun AnyLogic yazılımındaki görüntüsü Şekil 4’teki gibidir.

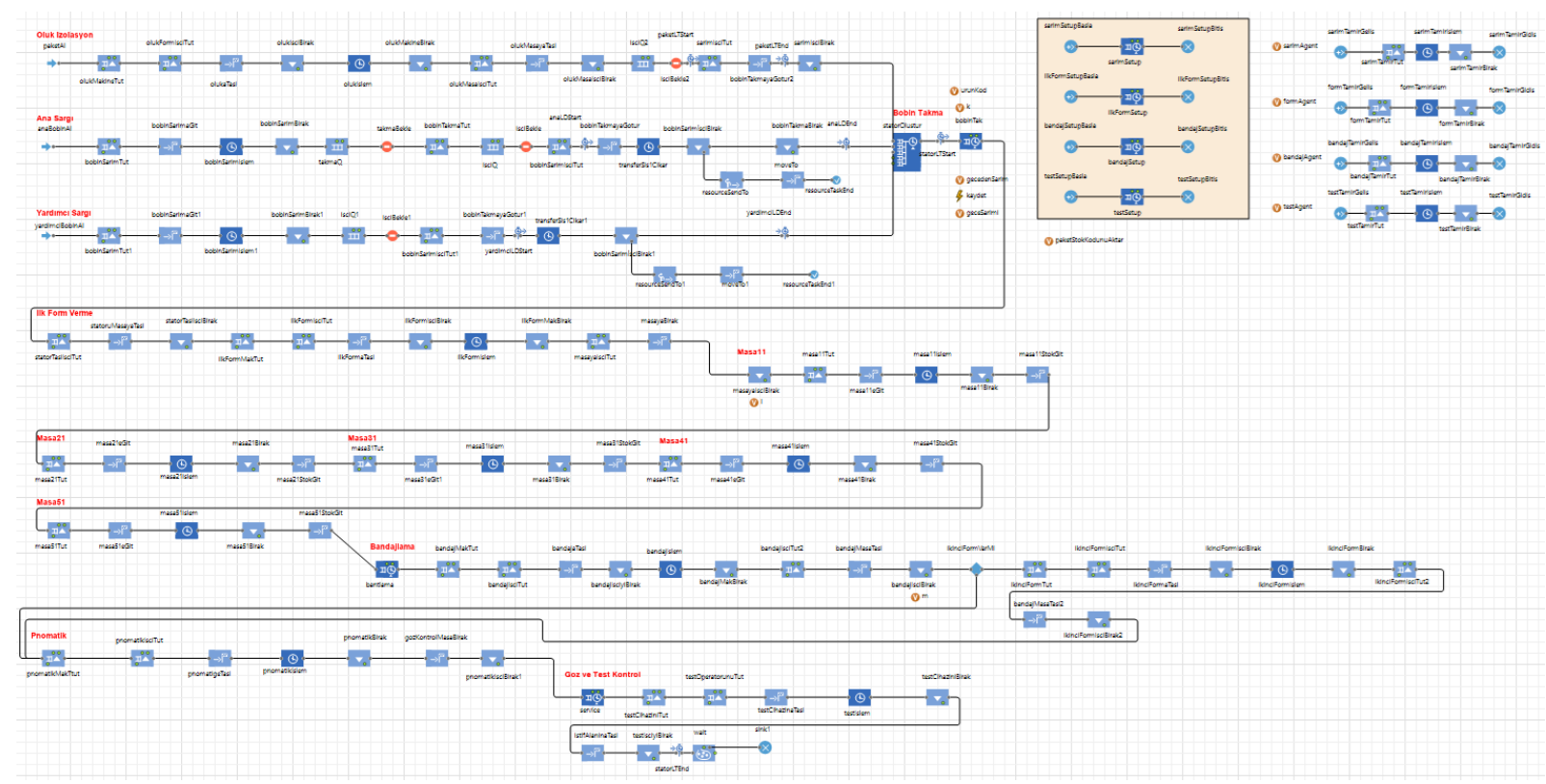

Şekil 4. AnyLogic ortamı

Simülasyon modelinin gerçek üretim hattını aynı şekilde yansıttığını ispat etme amacıyla doğrulama (verification) yapılmıştır. Modelde yer alan statorların (agent'ların), source bloğu ile yaratılıp sink bloğu ile yok edilmesi sürecindeki tüm akış, debug penceresiyle adım adım izlenmiştir. Agent'ların üretim hattındaki gerekli tüm adımlardan sırasıyla geçtikleri gözlemlenmiştir. Buradan, üretim hattının doğrulandığı sonucuna varılmıştır.

Modelden elde edilen çıktıların gerçek üretim hattına ait çıktılar ile kıyaslanmasının yapıldığı aşama ise geçerlilik (validation) aşamasıdır. Modelin geçerliliği için \%95 güven düzeyinde güven aralığı testi kullanılmıştır. Simülasyonun ve gerçek üretim hattının performans ölçülerinin yeterince yakın olup olmadığını değerlendirmek için güven aralığı testi uygulanır. Üretimde yapılan saha çalışması sonucunda bir vardiyada (440 dakika) 305 adet stator üretildiği kaydedilmiştir. Gözlemlenen bu değeri simülasyon çıtısı ile karşılaştırmak için stator üretim hattının simülasyon modeli $10 \mathrm{kez}$ tekrarlanmış \%95 güven düzeyinde güven aralığ tahmin edilmiştir. Şekil 5'te de gösterildiği gibi, bu güven aralığı gözlemlenen günlük üretimi kapsadığından, simülasyon modelinin gerçek üretim sistemini \%95 güven düzeyinde temsil ettiğini söylemek mümkündür.

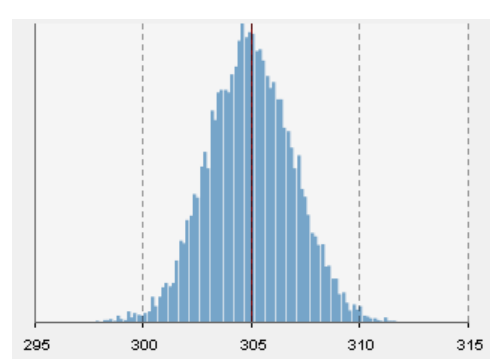

Şekil 5. \%95 güven aralığında vardiyalık üretim miktarı

\section{Modelin Çalıştırılması ve Bulgular}

Üretim hattındaki sarım makinesinin darboğaz olduğu doğrulanmış olup, Şekil 6'da gösterilmiştir. Sarım tezgahında yaşanan arıza sıklığının ve tamir sürelerinin uzun sürmesi, makinenin darboğaz olmasına neden olmuştur. Buna ek 
olarak ürünler arası geçişlerdeki tezgah hazırlık zamanları da uzundur.

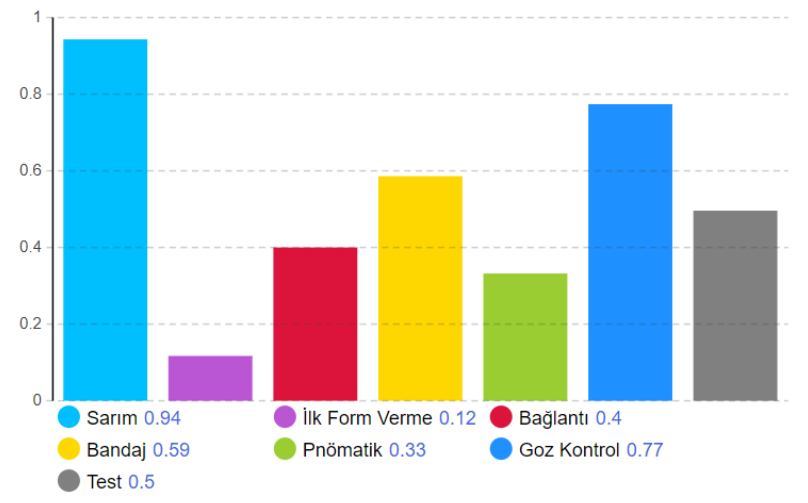

Şekil 6. Kaynak kullanım oranları

Simülasyon modeli, sarım makinesinin 3 vardiya ve diğer kaynakların 2 vardiya çalıştığı bir düzende aylık üretim planını gerçekleştirmiştir. Üretim planına uyum sağlanmıştır.
$\mathrm{Bu}$ çalışmanın amacı doğrultusunda, sarım makinesinin 3. vardiya üretim miktarının, özellikle bağlantıda çalışan operatörlerin kaynak kullanım oranına etkisi incelenmiştir. Çünkü bağlantıda çalışan operatörler, makinelerin sahip olduğu herhangi bir arıza ya da ürün değişimi gibi plansız duruşlara sahip değildir. Akış tipi üretim söz konusu olduğu için de, ürün, bağlantıdan bir sonraki sürece aktarılamadığında hat verimsiz olabilmektedir.

Sarımın bir vardiya fazla çalışarak gerçekleştirdiği ortalama üretim sayısı ile, bağlantı istasyonu önündeki ortalama stok miktarı da sistemin performansı için önemli bir ölçüttür. İlk 2 vardiya içerisinde bağlantı operatörleri, geceden sarılan ürünleri tüketirken, sarım makinesi stoka üretim yapıyormuş gibi akış devam etmektedir. Ancak bazı durumlarda bağlantı istasyonunun önündeki ürünler tamamlanıp sarım makinesi ile senkronize olurken, bazı durumlarda da arada belli bir miktarda stok olabilmektedir. İki durum da işletmenin istemediği bir durumdur. Burada önemli husus iki parametrenin başa baş noktasını bularak sistemi iyileştirmektir. Tablo 4'te üretim planındaki 17 ürünün üretimine ait performans göstergeleri paylaşılmış

Tablo 4. Modelin performans göstergeleri

\begin{tabular}{|c|c|c|c|c|c|c|c|c|c|c|c|c|}
\hline $\begin{array}{c}\text { Stok } \\
\text { Kodları }\end{array}$ & Adet & $\begin{array}{c}\text { Sarımın } \\
3 . \\
\text { vardiya } \\
\text { üretimi }\end{array}$ & $\begin{array}{c}\text { Bağlantı } \\
\text { öncesi } \\
\text { stok } \\
\text { miktarı }\end{array}$ & Sarım & $\begin{array}{c}\text { İlk } \\
\text { Form } \\
\text { Verme }\end{array}$ & Bağlantı & Bandaj & Pnömatik & $\begin{array}{l}\text { Göz } \\
\text { Kontrol }\end{array}$ & $\begin{array}{l}\text { Test } \\
\text { Kontrol }\end{array}$ & $\begin{array}{l}\text { Sarım } \\
\text { Ariza }\end{array}$ & $\begin{array}{l}\text { Sarım } \\
\text { Arıza } \\
\text { Süre } \\
\text { (dk) } \\
\end{array}$ \\
\hline VM11 & 501 & 0 & 0 & $91 \%$ & $13 \%$ & $64 \%$ & $52 \%$ & $30 \%$ & $70 \%$ & $44 \%$ & 2 & 16,36 \\
\hline VM12 & 3084 & 230 & 151 & $90 \%$ & $13 \%$ & $95 \%$ & $68 \%$ & $36 \%$ & $85 \%$ & $54 \%$ & 18 & 17,54 \\
\hline VM13 & 60 & 231 & 152 & $90 \%$ & $13 \%$ & $95 \%$ & $69 \%$ & $36 \%$ & $85 \%$ & $55 \%$ & 0 & 0 \\
\hline VM14 & 558 & 231 & 144 & $90 \%$ & $14 \%$ & $85 \%$ & $69 \%$ & $36 \%$ & $85 \%$ & $54 \%$ & 3 & 16,99 \\
\hline VM15 & 63 & 237 & 142 & $89 \%$ & $15 \%$ & $93 \%$ & $69 \%$ & $35 \%$ & $84 \%$ & $54 \%$ & 1 & 16,48 \\
\hline VM16 & 11 & 237 & 142 & $89 \%$ & $15 \%$ & $93 \%$ & $69 \%$ & $35 \%$ & $83 \%$ & $54 \%$ & 0 & 0 \\
\hline VM17 & 140 & 237 & 142 & $90 \%$ & $16 \%$ & $94 \%$ & $69 \%$ & $35 \%$ & $84 \%$ & $54 \%$ & 0 & 0 \\
\hline VM18 & 100 & 237 & 141 & $90 \%$ & $15 \%$ & $94 \%$ & $70 \%$ & $36 \%$ & $83 \%$ & $54 \%$ & 1 & 16,69 \\
\hline VM19 & 95 & 236 & 140 & $90 \%$ & $15 \%$ & $94 \%$ & $70 \%$ & $36 \%$ & $84 \%$ & $54 \%$ & 0 & 0 \\
\hline VM20 & 75 & 235 & 138 & $89 \%$ & $15 \%$ & $87 \%$ & $70 \%$ & $36 \%$ & $84 \%$ & $54 \%$ & 1 & 18,04 \\
\hline VM21 & 1293 & 227 & 124 & $88 \%$ & $14 \%$ & $27 \%$ & $65 \%$ & $37 \%$ & $86 \%$ & $56 \%$ & 10 & 17,88 \\
\hline VM22 & 35 & 227 & 124 & $88 \%$ & $14 \%$ & $26 \%$ & $65 \%$ & $37 \%$ & $86 \%$ & $56 \%$ & 1 & 17,67 \\
\hline VM23 & 62 & 226 & 124 & $88 \%$ & $14 \%$ & $25 \%$ & $65 \%$ & $38 \%$ & $86 \%$ & $56 \%$ & 0 & 0 \\
\hline VM24 & 303 & 211 & 113 & $88 \%$ & $13 \%$ & $32 \%$ & $60 \%$ & $35 \%$ & $81 \%$ & $53 \%$ & 4 & 17,26 \\
\hline VM25 & 42 & 208 & 111 & $88 \%$ & $13 \%$ & $26 \%$ & $59 \%$ & $34 \%$ & $79 \%$ & $52 \%$ & 1 & 17,21 \\
\hline VM26 & 61 & 202 & 108 & $88 \%$ & $13 \%$ & $93 \%$ & $59 \%$ & $34 \%$ & $79 \%$ & $52 \%$ & 2 & 17,3 \\
\hline VM27 & 5 & 202 & 108 & $88 \%$ & $13 \%$ & $93 \%$ & $59 \%$ & $34 \%$ & $79 \%$ & $52 \%$ & 2 & 17,3 \\
\hline
\end{tabular}


Tablo 4 incelendiğinde;

- IIlk siparişe ait 501 adet üretim, bir günde, 3. vardiyaya ihtiyaç olmadan tamamlanmıştır. O siparişin tamamlanma zaman aralığına ait kaynakların kullanım oranları ile sarım makinesinin arıza sayısı ve süreleri verilmiştir. Sarım makinesi 3. vardiya çalışmadığ iç̧in özellikle bağlantının kullanım oranı düşüktür.

- 2. sipariş 6 günde tamamlanmış olup üretimi boyunca sarım makinesi gece de çalışmıştır. 6 gün boyunca sarım makinesi ortalama 230 ürünü 3 . vardiya üretmiştir ve bağlantı iş merkezinin önünde ortalama 151 ürün bulunmuştur. $\mathrm{Bu}$ durumda, bağlantıdaki operatörlerin kullanım oranları \%100'e yaklaşmıştır.

- Kırmızı ile işaretlenen sipariş gerçekleştiği sırada sarım tezgahında 10 defa arıza gerçekleşmiş (ortalama 17,88 dakika sürmüş) ve bu durum siparişin üretildiği 2 günü etkilemiştir. Bunun sonucunda da bağlantı kullanım oranı ciddi düşüş yaşamıştır. Geçmiş dönemde fazladan üretim gerçekleştirilmiş, bir başka deyişle daha fazla ara stok miktarı bulundurulmuş olsa, kaynakların kullanım oranlarının bu kadar düşmesinin önüne geçilebileceği düşünülmektedir.

Bağlantı kaynaklarının ideal kullanım oranına sahip olduğu ancak stok miktarının da minimum seviyede bulunduğu bir sistemde, stok miktarının kaç olması gerektiği üzerinde deney tasarımları (experimental design) gerçekleştirilmiştir. Model değişen girdiler ile defalarca çalıştırılmış ve elde edilen çıktılar Şekil 7'de özetlenmiştir:

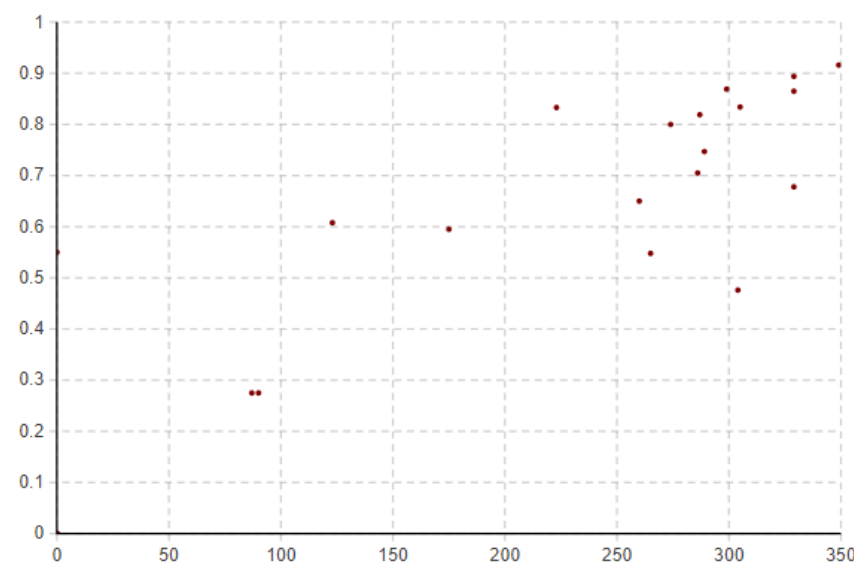

Şekil 7. Sarım makinesinin üretim miktarı ile bă̆lantının kullanım oranı ilişkisi

Şekil 7'de x ekseni geceden sarılan ürün miktarını gösterirken y ekseni ise bağlantıdaki operatörlerin kullanım oranını göstermektedir. Beklendiği gibi geceden sarım artmaya başladığında bağlantının kullanım oranının da arttığı görülmektedir.

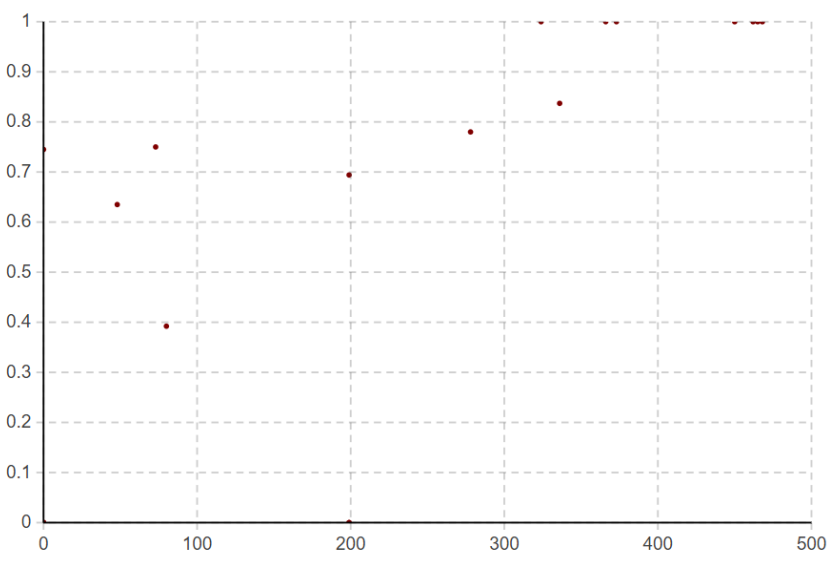

Şekil 8. Ideal üretim adedi

Yukarıdaki grafik ise farklı bir deneyde elde edilmiş olup, 3. vardiya sarım miktarının arttığı durumda, bağlantı iş merkezinin kullanım oranını yansıtmaktadır. Miktar 375'in üzerine çıktığı zaman bağlantı kullanım oranı \%100'e sabitlemekte olup, bu miktardan sonra üretim gerçekleştirmenin bağlantı kullanım oranı üzerinde etkisinin olmadığı görülmektedir. Aksine üretilen ürünler işletmeye stok bulundurma maliyeti olarak yansımaktadır. 375 adedi de sarım makinesinin bir vardiyada çıkarabildiği simülasyonda teyit edilmiştir.

\subsection{Alternatif İyileştirme Önerisi}

Kaynakların kullanım oranları incelendiğinde, düşük kullanım oranına sahip başka kaynaklar da olduğu tespit edilmiştir. İlk form vermeyi yapan operatörün kullanım oranı simülasyon deneyleri sırasında hiç \%20’i geçmemiştir. Benzer şekilde pnömatik form vermeyi yapan operatörün de kullanım oranı \%38 civarındadır. Model burada iyileştirmenin mümkün olduğunu göstermektedir.

Bunun için hat yerleşiminde değişikliğe giderek ilk form verme ve pnömatik makinelerine bakan operatör sayısı 2'den 1'e düşürülmüştür.

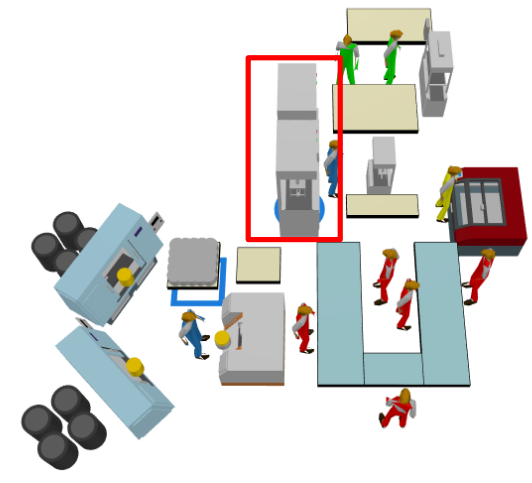

Şekil 9. Alternatif yerleşim önerisi ve operatör kazancl

Üretim adedi değişmeksizin bu yeni yerleşimle bir operatör sistemden çıkarılarak maliyet kazancı sağlanmıştır. Son durumda iki makineye bakan operatörün kullanım oranı da $\% 48$ olmuştur.

\section{Sonuç}

$\mathrm{Bu}$ çalışmada, kesikli olay simülasyonu ile elektrik motoru üreten bir firmanın stator yarı mamulünün üretildiği bir üretim hattı modellenmiştir. 8 makine ve 11 operatörün yer aldığı bu 
hatta akış tipi üretim yapılmaktadır. Hatta ilişkin geçmiş bir yılın verileri kullanılmıştır. Modelde yer alan parametrelerden iş merkezlerine ait operasyon süreleri, makinelerin arıza olasılıkları ve tamir süreleri, ürünler arası geçişlerdeki makine hazırlık sürelerinin olasılık dağılımları belirlenmiş ve bu parametreler modele olasılık dağılımları ile entegre edilmiştir. Simülasyon modeli ile bir aylık üretim planı gerçekleştirilmiştir. Ele alınan bir aylık dönemde hatta üretilen ürünlerin talep miktarları da modelde kullanılmıştır. Simülasyon modelinin doğrulanması ve geçerliliğinin test edilmesinin ardından model çalıştırılmıştır. Mevcut durumun performansı, iş merkezlerinin kullanım oranları, operatörlerin kullanım oranları, bağlantı öncesi stok miktarları, sarım makinesi arıza sayıları ve arızaların süreleri açılarından değerlendirilmiştir. Bulgular, hatta yer alan sarım makinesinin darboğaz olduğuna işaret etmektedir. Aynı zamanda, hattın verimliliği açısından kilit önem taşıyan bağlantı operasyonu ve o operasyonda çalışan operatörlerin kullanım oranları ile sarım makinesinin üretim miktarı arasındaki ilişki analiz edilmiştir. Analiz sonucunda bağlantı kaynak kullanımını maksimize edecek sarım miktarı belirlenmiştir. Operatörlerin kaynak kullanım oranları dikkate alınarak, hat için, düşük kullanım oranına sahip operatörlerin kullanım oranlarını artırmayı hedefleyen yeni bir yerleşim önerilmiştir. Bu yerleşimde ilk form verme ve pnömatik makinelerine bakan operatör sayısı 2'den 1'e düşürülmüştür. $\mathrm{Bu}$ sayede hem bir operatör daha az kullanılarak maliyet düşüşü, hem de operatör kullanım oranında artış sağlanmıştır.

\section{Teşekkür}

$\mathrm{Bu}$ çalışmaya verdiği destekten dolayı Volt Elektrik Motor San. Tic. A.Ş.' ye teşekkür ederiz.

\section{Kaynakça}

[1] Xu, L. D., Xu, E. L., \& Li, L. (2018). Industry 4.0: state of the art and future trends. International Journal of Production Research, 56(8), 2941-2962.

[2] Theorin, A., Bengtsson, K., Provost, J., Lieder, M., Johnsson, C., Lundholm, T., \& Lennartson, B. (2017). An event-driven manufacturing information system architecture for Industry 4.0. International journal of production research, 55(5), 1297-1311.

[3] Lai, X., Shui, H., Ding, D., \& Ni, J. (2021). Data-driven dynamic bottleneck detection in complex manufacturing systems. Journal of Manufacturing Systems, 60, 662-675.

[4] Pehrsson, L., Ng, A. H., \& Bernedixen, J. (2016). Automatic identification of constraints and improvement actions in production systems using multi-objective optimization and post-optimality analysis. Journal of manufacturing systems, 39, 24-37.

[5] Goldratt, E. M. (1990). Theory of constraints (pp. 1-159). Croton-on-Hudson: North River.

[6] Leporis, M., \& Králová, Z. (2010). A simulation approach to production line bottleneck analysis. In International conference cybernetics and informatics (pp. 13-22).

[7] Li, L. (2009). Bottleneck detection of complex manufacturing systems using a data-driven method. International Journal of Production Research, 47(24), 6929-6940.

[8] Li, L., Chang, Q., \& Ni, J. (2009). Data driven bottleneck detection of manufacturing systems. International Journal of production research, 47(18), 5019-5036.
[9] Vazan, P., Znamenak, J., \& Juhas, M. (2018, September). Proactive Simulation in Production Line Control. In 2018 IEEE 13th International Scientific and Technical Conference on Computer Sciences and Information Technologies (CSIT) (Vol. 1, pp. 52-55). IEEE.

[10] W. Zhou, S. Q. Li, Y. Q. Huang, and J. F. Wang, "Simulation Based Capacity Optimization of a General Assembly Line with Extremely Unbalanced Station Process Time," In 2019 IEEE International Conference on Industrial Engineering and Engineering Management (IEEM) (pp. 1245-1249), 2019, IEEE.

[11]Al-Khafaji, S. K., \& Al-Rufaifi, H. M. (2012, July). A Case Study of Production Improvement by Using Lean with Simulation Modeling. In Proceedings of the 2012 International Conference on Industrial Engineering and Operations Management. Istanbul, Turkey (pp. 271-279).

[12]Kulkarni, R. G., Kulkarni, V. N., \& Gaitonde, V. N. (2018). Productivity improvement in assembly workstation of motor winding unit. Materials Today: Proceedings, 5(11), 2351823525 .

[13]Heshmat, M., El-Sharief, M., \& El-Sebaie, M. (2017). Simulation modelling and analysis of a production line. International Journal of Simulation and Process Modelling, 12(3-4), 369-376.

[14]Damiani, L., Demartini, M., Giribone, P., Maggiani, M., Revetria, R., \& Tonelli, F. (2018). Simulation and digital twin based design of a production line: A case study. In Proceedings of the International MultiConference of Engineers and Computer Scientists (Vol. 2).

[15] Öner-Közen, M., Minner, S., \& Steinthaler, F. (2017). Efficiency of paced and unpaced assembly lines under consideration of worker variability-A simulation study. Computers \& Industrial Engineering, 111, 516-526.

[16] Opacic, L., Sowlati, T., \& Mobini, M. (2018). Design and development of a simulation-based decision support tool to improve the production process at an engineered wood products mill. International journal of production economics, 199, 209-219.

[17]Singh, N., Herps, K., Martagan, T., \& Adan, I. J. (2019, December). > Simulation-Based Performance Evaluation of A Manufacturing Facility with Vertical As/Rs. In 2019 Winter Simulation Conference (WSC) (pp. 2001-2012). IEEE.

[18]Allgeier, H., Flechsig, C., Lohmer, J., Lasch, R., Schneider, G., \& Zettler, B. (2020, December). Simulation-Based Evaluation of Lot Release Policies in a Power Semiconductor Facility-a Case Study. In 2020 Winter Simulation Conference (WSC) (pp. 1503-1514). IEEE.

[19] AnyLogic website. [Online]. Available: https://www.anylogic.com

[20]A. Kampa, A., Gołda, G., \& Paprocka, I. (2017). Discrete event simulation method as a tool for improvement of manufacturing systems. Computers, 6(1), 10. 